\title{
Identification of icp11, the most highly expressed gene of shrimp white spot syndrome virus (WSSV)
}

\author{
Han-Ching Wang ${ }^{1}$, Hao-Ching Wang ${ }^{2}$, Guang-Hsiung Kou ${ }^{1}$, Chu-Fang Lo ${ }^{1}$, \\ Wei-Pang Huang ${ }^{1, *}$
}

${ }^{1}$ Institute of Zoology, and ${ }^{2}$ Institute of Biochemical Sciences, National Taiwan University, No. 1, Sec. 4, Roosevelt Road, Taipei 10617, Taiwan

\begin{abstract}
This study investigates white spot syndrome virus (WSSV) gene expression levels in the cells of 2 hosts (Penaeus monodon and Litopenaeus vannamei). Microarray and expressed sequence tag (EST) analysis of the mRNA profiles in WSSV-infected P. monodon cells were used to identify WSSV genes that were very highly expressed. Results showed that the mRNA of the WSSV icp11 gene consistently had the highest copy number of all $(3 \times$ higher than the major envelope protein, VP28). At the protein level in WSSV-infected L. vannamei, 2-dimensional gel analysis and liquid chromatography-nano-electrospray ionization tandem mass spectrometry (LC-nanoESI-MS/MS) protein identification also showed that this WSSV non-structural protein has the highest expression levels reported to date. ICP11 is capable of self-multimerization, and it becomes located in both the cytoplasm and nucleus of the host cell. These data suggest that ICP11 plays an important, but presently unknown, role during viral infection, and that expression of the WSSV icp11 gene/WSSV ICP11 protein is potentially a good and diagnostically useful indicator of WSSV infection.
\end{abstract}

KEY WORDS: Penaeus monodon · White spot syndrome virus · WSSV · icp11 · Immuno-based detection

\section{INTRODUCTION}

Although shrimp aquaculture is important in much of Asia, it continues to be threatened by several viral shrimp diseases, including white spot disease (WSD) (Chang et al. 1995, Wang et al. 1995, Wongteerasupaya et al. 1995, Lo et al. 1997, Lu et al. 1997, Lo \& Kou 1998, Sangamaheswaran \& Jeyaseelan 2001, Liu et al. 2005). The causative agent of this disease, white spot syndrome virus (WSSV), is the type species of the genus Whispovirus, family Nimaviridae (Vlak et al. 2004). WSSV is a large DNA virus with a virion that consists of a nucleocapsid, tegument and envelope, and includes at least 39 structural proteins (Tsai et al. 2004, 2006, Leu et al. 2005).

When WSD first appeared in 1992, it caused tremendous economic losses, and the aquaculture industry responded by completely changing the traditional ways in which shrimp were managed (Lightner 2003).
One change in particular was the increased emphasis on aquatic animal disease surveillance, and this, in turn, led to a demand for non-destructive molecular diagnostic tests to screen broodstock and postlarvae. Nested polymerase chain reaction (PCR) tests are now commercially available for most of the economically important crustacean viruses, including WSSV (Hsu et al. 1999, Chen et al. 2000, Peng et al. 2001). However, although these diagnostic kits are routinely used in research laboratories, the associated costs and technical expertise required have prevented their widespread adoption in traditional farms. It would therefore be very helpful to develop a diagnostic test that is not only highly sensitive and rapid, but also cheap and easily performed.

An immuno-based detection system is a good candidate for such a test. The sensitivity of this kind of test depends on the immuno-detected target protein, and several candidate proteins have already been conside- 
red. Liu et al. (2002) and Yoganandhan et al. (2004) independently developed procedures that targeted the WSSV major envelope protein, VP28, while Okumura et al. (2005) developed a reverse passive latex agglutination method to detect WSSV virion particles by using anti-WSSV immunoglobulin G (IgG). All 3 of these studies were based on WSSV structural proteins, which until now were thought to be the most highly expressed proteins of WSSV. Here, we use a systematic approach to detect a WSSV gene/protein that is more highly expressed than any structural gene/protein, and which should therefore be a good candidate for improved RNA-based and immuno-based diagnostic tests.

In this study, we used both microarray and expressed sequence tag (EST) analysis of the mRNA profiles of WSSV-infected cells to identify WSSV genes that are very strongly expressed at the transcription level. Twodimensional electrophoresis (2-DE) gel analysis and liquid chromatography-nano-electrospray ionization tandem mass spectrometry (LC-nanoESI-MS/MS) protein identification were then used to confirm that high expression levels are also found for one of these genes at the translation level. Western blotting was used to compare the relative abundance of this candidate protein and VP28 in gill tissues, as well as in other organs, such as pleopods, which can be safely and easily collected from shrimps for screening purposes. We conclude that a non-structural protein, ICP11, is likely to be a better indicator of WSSV infection than VP28. We consider the potential of this gene/protein in the development of RNA-based or rapid immuno-based detection systems for WSSV.

\section{MATERIALS AND METHODS}

Virus, virus inoculum and experimental shrimp. The virus used in this study was WSSV T-1 isolate (GenBank Accession Number AF440570) (Wang et al. 1995, Lo et al. 1999, Chen et al. 2002). WSSV inoculum was prepared as described previously and stored at $-80^{\circ} \mathrm{C}$ until use (Tsai et al. 1999). The experimental inoculum was then prepared from the supernatant of this stock after centrifugation at $400 \times g$ for $10 \mathrm{~min}$ at $4^{\circ} \mathrm{C}$ and further dilution $\left(10^{-2}\right)$ with phosphatebuffered saline (PBS).

The experimental shrimp used in the study were adult Penaeus monodon (mean weight: $20 \mathrm{~g}$ ) and Litopenaeus vannamei (mean weight: $2.6 \mathrm{~g}$ ). Challenge

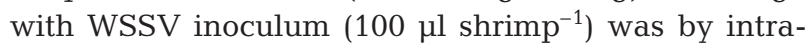
muscular injection following Tsai et al. (1999). Shrimp injected with PBS vehicle only were used as controls. At 24,36 and 48 hpi (hours post-infection), the gills and other tissues of the challenged and control shrimps were collected and frozen using liquid nitrogen.
WSSV gene DNA microarray chip preparation, target preparation, hybridization, scanning and statistical analysis. Duplicate sets of WSSV DNA microarray chips were prepared as described previously, with 532 WSSV open reading frames (ORFs) plus a shrimp (Penaeus monodon) beta-actin gene, each represented by 3 spots (Tsai et al. 2004, Wang et al. 2004, Liu et al. 2005). For the cDNA targets, total RNA was extracted from gill tissues of control and WSSV-challenged $P$. monodon shrimp at 0 and $24 \mathrm{hpi}$, respectively. A postinfection time of $24 \mathrm{~h}$ was chosen because pilot studies produced well-differentiated results at this time, whereas at 36 hpi the signal intensities of most spots were already saturated. These RNA samples (20 $\mu \mathrm{g}$ for each reaction) were reverse-transcribed and fluorescently labeled with Cy3-dUTP using a CyScribe FirstStrand cDNA-labeling kit (Amersham Biosciences). After the Cy3-labeled cDNA targets had been condensed, the unincorporated nucleotides were removed using Microcon YM-30 columns (Amicon), and the samples were subjected to hybridization with all of the DNA spots in the WSSV DNA microarray chip. The microarrays were scanned with a confocal laser (ScanArray 3000 system), and the fluorescence intensities in each spot were quantified by Imagen 4.0 (Biodiscovery). The signal intensities were normalized across the slides by using the beta-actin gene as the normalization factor. For each WSSV gene transcript in the infected shrimp gill tissues, the mean $(n=3)$ fluorescence intensity results are expressed as percentages relative to the signal intensity of the shrimp beta-actin gene on the same chip.

Construction of a WSSV-infected Penaeus monodon postlarvae cDNA library and EST database. For this study, we used a single cDNA library, PmTwI, which had been constructed previously from WSSV-infected $P$. monodon postlarvae (PL20) using a $\lambda$-Zap II vector construction kit (Stratagene), followed by conversion to the pBluescript plasmid by mass excision, according to the manufacturer's instructions. From this library, a total of 7632 ESTs were obtained by subjecting randomly selected clones to $3^{\prime}$ sequencing. Phred $(Q>13)$, the 'Cross_match' package with default parameters (minimatch 12 , penalty -2 , miniscore 20 ) and the Prap assembly program were run to yield a total of 2237 unique sequences in PmTwI. These sequences were examined for matches in the GenBank nr (non-redundant) peptide sequence database and SWISS PROT using BlastX and InterPro Scan with default parameters.

Two-dimensional electrophoresis. The experimental shrimp used in this assay were the offspring (mean body weight: $2.6 \mathrm{~g}$ ) of Litopenaeus vannamei brooders purchased from High Health Aquaculture. For each 2-DE, the frozen gills taken at $48 \mathrm{hpi}$ from $3 \mathrm{WSSV}$ challenged and 3 control (PBS-only) shrimp were 
ground to a fine powder at $-80^{\circ} \mathrm{C}$. The powder was then suspended in a 3-fold dilution of PBS buffer containing protease inhibitor cocktail (applied according to the manufacturer's protocol, Roche Diagnostics). After centrifugation at $3000 \times g\left(30 \mathrm{~min}, 4^{\circ} \mathrm{C}\right)$, the supernatant was collected and a trichloroacetic acid/ dithiothreitol (TCA/DTT) mixture was added (final concentration: $10 \% \mathrm{w} / \mathrm{v}$ trichloroacetic acid and $0.1 \%$ dithiothreitol). After standing on ice for $30 \mathrm{~min}$ and another procedure of centrifugation $(10000 \times g$, $30 \mathrm{~min}, 4^{\circ} \mathrm{C}$ ), the supernatant was discarded and the pellet resuspended in acetone containing $0.1 \%$ DTT. The sample was spun again $\left(10000 \times g, 30 \mathrm{~min}, 4^{\circ} \mathrm{C}\right)$, and the pellet was dried under vacuum and then dissolved in rehydration buffer (9.8 M urea, 2\% CHAPS, $20 \mathrm{mM}$ DTT, $0.5 \%$ immobilized $\mathrm{pH}$ gradient [IPG] buffer [pH 3 to 10; Amersham Biosciences]). After a final centrifugation $\left(10000 \times g, 30 \mathrm{~min}, 15^{\circ} \mathrm{C}\right)$, the supernatant, which contained the soluble protein fraction, was used as a 2-DE sample. Protein concentration of 2-DE samples was estimated using a 2-D Quant Kit (Amersham Biosciences).

The first dimension of the 2-DE, isoelectric focusing (IEF), was performed in $13 \mathrm{~cm}$ Immobiline DryStrip gel (Amersham Biosciences) using an integrated system, the Ettan IPGphor (Amersham Biosciences), whereby rehydration with the sample and IEF are performed automatically. Linear pH 3 to 10 gradient strips were used. Each sample (250 $\mathrm{\mu g}$ protein) was dissolved in $250 \mu \mathrm{l}$ rehydration buffer with a trace of bromophenol blue and placed in the base well of an IPGphor stripholder. An IPG strip was then placed on the top of the sample, and, after rehydration in the IPGphor (16 h at $50 \mathrm{~V}$ ), automatic IEF was performed using the following step voltage focusing protocol: $1 \mathrm{~h}$ at $300 \mathrm{~V}, 1 \mathrm{~h}$ at $500 \mathrm{~V}, 2 \mathrm{~h}$ at $1000 \mathrm{~V}, 2 \mathrm{~h}$ at $4000 \mathrm{~V}$ and $10 \mathrm{~h}$ at $8000 \mathrm{~V}$. All the above procedures were carried out at $20^{\circ} \mathrm{C}$. After the first dimensional IEF, the IPG strips were equilibrated in a sodium dodecyl sulfate (SDS) equilibration buffer (6 M urea, 2\% SDS, 30\% glycerol, $50 \mathrm{mM}$ Tris- $\mathrm{HCl}, \mathrm{pH} 8.8$ ) containing $1 \%$ DTT for $15 \mathrm{~min}$. The IPG gel strips were then removed to another equilibration buffer containing $2.5 \%$ iodoacetamide and equilibrated for a further $15 \mathrm{~min}$. The equilibrated IPG strips were then placed onto a polyacylamide gel that consisted of $14 \%$ acylamide, $\mathrm{pH} 8.8$, for the separating gel, and $4 \%$ acylamide, $\mathrm{pH} 6.8$, for the stacking gel. The second dimensional separation was run at $20 \mathrm{~mA}$ per gel at $15^{\circ} \mathrm{C}$ for 5 to $6 \mathrm{~h}$. At the end of each run, the gels were stained with sypro ruby, and the protein patterns of the gels were scanned using a Typhoon 9400 scanner (Amersham Biosciences). Gel image matching was done using PDQuest software (Bio-Rad).

In-gel protein digestion and protein identification. Protein spots of interest were manually excised from the gels, washed twice with $25 \mathrm{mM}$ ammonium bicarbonate buffer ( $\mathrm{pH} 8.5$ ) in $50 \%$ acetonitrile, for $15 \mathrm{~min}$ each time, dehydrated with $100 \%$ acetonitrile for $5 \mathrm{~min}$, vacuum dried and rehydrated with $100 \mathrm{ng}$ of sequencing-grade, modified trypsin (Promega) in $25 \mathrm{mM}$ ammonium bicarbonate, $\mathrm{pH} 8.5$, at $37^{\circ} \mathrm{C}$ for $16 \mathrm{~h}$. Following digestion, tryptic peptides were extracted twice with $5 \%$ formic acid in $50 \%$ acetonitrile for $15 \mathrm{~min}$ each time with sonication. The extracted solutions were pooled and evaporated to dryness under vacuum. Samples were dissolved in $0.1 \%$ formic acid in $50 \%$ acetonitrile and analyzed by LC-nanoESI-MS/MS. Proteins were identified by MS/MS ion search using the search program Mascot. For MS/MS ion search, the mass tolerance parameter was $0.25 \mathrm{Da}$, MS/MS ion mass tolerance was $0.25 \mathrm{Da}$, and up to 1 missed cleavage was allowed. Variable modifications considered were methionine oxidation and cysteine carboxyamidomethylation. Significant hits (as defined by Mascot probability analysis) were regarded as positive identification.

Mapping the $5^{\prime}$ and $3^{\prime}$ termini of the WSSV icp11 transcript. At $36 \mathrm{~h}$ after WSSV infection almost every WSSV gene is expressed (Wang et al. 2004), so at this time, RNA samples were taken from WSSV-infected Penaeus monodon shrimp. From these samples, the $5^{\prime}$ and $3^{\prime}$ untranslated regions of the WSSV icp11 transcript were obtained by rapid amplification of the cDNA $5^{\prime} / 3^{\prime}$ ends using a commercial $5^{\prime}$ and $3^{\prime}$ rapid amplification of cDNA ends (RACE; Roche Molecular Biochemicals). The 5' RACE protocol was slightly modified for WSSV icp11 because the $5^{\prime}$ untranslated region incorporates long stretches of thymidines, which may cause non-specific binding of the oligo(dT)anchor primer to the cDNA. Accordingly, the cDNA of WSSV icp11 was 3'-tailed, with dCTPs rather than dATPs, and the oligo(dG)-anchor primer was used in the PCR reaction. The PCR products were cloned in a pGEM-T Easy vector and sequenced.

Purification of the native form of rICP11. An WSSV ICP11 expression construct was formed by digesting the amplified WSSV ICP11 fragment using NdeI and XhoI and ligating it between the NdeI and XhoI sites of pET28b. An excess of recombinant WSSV ICP11 protein (rICP11) was produced in Escherichia coli strain BL21(DE3) codon plus, with $0.1 \mathrm{mM}$ isopropylthiogalactoside at $37^{\circ} \mathrm{C}$ for $3 \mathrm{~h}$. Following centrifugation, E. coli cell pellets were resuspended in lysis buffer $\left(50 \mathrm{mM} \mathrm{NaH}_{2} \mathrm{PO}_{4}, 300 \mathrm{mM} \mathrm{NaCl}, 10 \mathrm{mM}\right.$ immidazole, $\mathrm{pH}$ 8.0) and sonicated on ice. The cell debris was removed by centrifugation. The supernatant was loaded onto a HisPrep ${ }^{\mathrm{TM}}$ FF 16/10 column (Amersham Biosciences) and washed with washing buffer $(50 \mathrm{mM}$ $\mathrm{NaH}_{2} \mathrm{PO}_{4}, 300 \mathrm{mM} \mathrm{NaCl}, 20 \mathrm{mM}$ immidazole, $\mathrm{pH}$ 8.0), and then rICP11 was eluted with elution buffer $(50 \mathrm{mM}$ 
$\mathrm{NaH}_{2} \mathrm{PO}_{4}, 300 \mathrm{mM} \mathrm{NaCl}, 500 \mathrm{mM}$ immidazole, $\mathrm{pH}$ 8.0). The fractions were collected, pooled and dialyzed against PBS. This protein was used for antibody production and multimerization assay.

Western blot analysis and protein dot-blot analysis to detect WSSV ICP11 in shrimp tissue. Although preliminary assays showed that Western blotting could detect ICP11 as early as $18 \mathrm{hpi}$, the WSSV protein used for comparison (VP28) could not be detected in the 24 or $40 \mu \mathrm{g}$ samples until $48 \mathrm{hpi}$. Therefore, for this assay, tissue samples were taken from the lymphoid organ, stomach, midgut, heart, gill, epidermis, pleopod, hepatopancreas and nervous tissue of WSSV-infected shrimp (Penaeus monodon) at $48 \mathrm{hpi}$. The tissue samples were homogenized in lysis-PBS buffer (PBS diluted $3 \times$ in $\mathrm{ddH}_{2} \mathrm{O}$ at $\left.4^{\circ} \mathrm{C}\right)$ and centrifuged $\left(10000 \times g_{\text {i }}\right.$ $15 \mathrm{~min}$ ), and the supernatants were collected. Samples (24 $\mathrm{\mu g}$ total protein) were mixed with SDS-sample buffer $(1 \%$ SDS, $15 \%$ glycerol, $10 \mathrm{mM}$ Tris-HCl [pH 6.8], 10\% beta-mercaptoethanol), separated on $17.5 \%$ SDS-PAGE (sodium dodecyl sulfate polyacrylamide gel electrophoresis) and transferred onto a PVDF (polyvinylidene difluoride) membrane by semidry blotting. The membrane was blocked using blocking buffer (5\% skim milk and $3 \%$ normal goat serum in TBST [0.5\% Tween 20, $200 \mathrm{mM} \mathrm{NaCl}, 50 \mathrm{mM}$ Tris- $\mathrm{HCl}$, pH 7.5]) for $16 \mathrm{~h}$ at $4^{\circ} \mathrm{C}$, and was then incubated with primary antibody at a dilution of 1/5000 in blocking buffer for $1 \mathrm{~h}$ at room temperature. After washing twice in TBST, the membrane was incubated with secondary antibody conjugated with horseradish peroxidase (HRP) at a concentration of 1/5000 in TBST. Lastly, the membrane was washed twice more with TBST, and an enhanced chemiluminescence system (NEN Life Products) was used for detection.

Some of the gill tissue samples prepared as described above were also subjected to protein dot-blot analysis. For this analysis, the total protein lysates were serially diluted (200 to $0.05 \mu \mathrm{g}$ ) and vacuum blotted directly without SDS sample buffer onto PVDF membrane that had been cut, soaked in methanol for $5 \mathrm{~min}$ and mounted into a dot-blot hybridization instrument (Minifold I 96-well dot-blot system, Schleicher-Schuell). Incubation, antibody reaction and detection were the same as described above for Western blotting.

Indirect immunofluorescence assay of WSSV ICP11 in shrimp hemocytes. Hemolymph was collected from healthy Penaeus monodon shrimp and from WSSV-infected shrimp at $24 \mathrm{hpi}$ using a syringe that contained cold modified Alsever solution (Lin et al. 2002). Hemocytes were placed on glass coverslips, washed with PBS and fixed in $4 \%$ paraformaldehyde for $10 \mathrm{~min}$ at $4^{\circ} \mathrm{C}$. After acetone treatment ( $3 \mathrm{~min}$ on ice), the hemocytes were incubated with $3 \%$ normal goat serum for $16 \mathrm{~h}$ at $4^{\circ} \mathrm{C}$ to prevent non-specific antibody adsorption. After this blocking, the hemocytes were incubated for 3 to $4 \mathrm{~h}$ at room temperature with a 1/500 dilution of rICP11-specific rabbit antiserum. Following 2 washes, each for 15 min in PBST (PBS containing 0.3\% Tween-20), the cells were incubated for $1 \mathrm{~h}$ with a 1/200 dilution of fluorescein isothiocyanate (FITC)-conjugated polyclonal goat anti-rabbit IgG. Following extensive washing with PBST, the cells were mounted and viewed using an Olympus microscope. Then, 4', 6-diamidino-2-phenylindole (DAPI) was used to counterstain the nucleus.

Analysis of the multimeric nature of native WSSV rICP11. Since the functionality of some proteins is affected by multimerization, here we used a chemical cross-linking assay to investigate the multimeric nature of rICP11 (Kaukinen et al. 2001). Briefly, $10 \mu \mathrm{l}$ samples of $\mathrm{rICP} 11\left(1 \mathrm{\mu g} \mathrm{\mu l}^{-1}\right)$ were incubated with 0.01 to ca. $1 \mathrm{mM} \mathrm{BS}^{3}$ (bis[sulfosuccinimidyl] suberate; Pierce) in PBS (30 min, room temperature). The samples were treated with reducing sample buffer (0.125 M Tris, pH 6.8, 4\% SDS, 20\% glycerol, $10 \%$ beta-mercaptoethanol, $0.01 \%$ bromophenol blue), heated $\left(100^{\circ} \mathrm{C}, 5 \mathrm{~min}\right)$ and then separated on SDS $-17.5 \%$ acrylamide gels. Immunoblotting was performed with WSSV ICP11-specific polyclonal antibody with HRP-conjugated goat anti-rabbit serum. The reactions were detected using an enhanced chemiluminescence system (NEN Life Products).

In addition, the recombinant protein was also resuspended in sample buffer (1\% SDS, $15 \%$ glycerol, $10 \mathrm{mM}$ Tris- $\mathrm{HCl}$ [pH 6.8]) with or without $1 \%$ betamercaptoethanol, and with or without heating at $100^{\circ} \mathrm{C}$ for 5 min (Hassan \& Roy 1999). Samples (20 $\mu$ g protein) were then loaded onto acrylamide gels $(17.5 \%)$ and subjected to electrophoresis followed by Western blotting with WSSV ICP11-specific antibodies.

\section{RESULTS}

\section{Microarray and EST screening for highly expressed WSSV genes}

A total of 48 WSSV genes were identified from the 2237 unique sequences in the PmTwI library, and the 20 genes with the highest in silico expression profile are listed in Table 1. Since the cDNA clones selected for sequencing were chosen at random, their relative abundance in an unamplified library (i.e. their in silico expression profile in Table 1) should reflect the corresponding transcript levels (Yu et al. 2003). The data in Table 1 therefore suggest that icp11 (EST redundancy = 29) was the most strongly expressed WSSV gene, with expression levels nearly $3 \times$ greater than $v p 35$ $($ EST redundancy $=11)$ and more than $3 \times$ greater than the WSSV major envelope protein gene vp28 (EST 
Table 1. Comparison of 20 highly expressed genes of white spot syndrome virus (WSSV) as determined by expressed sequence tags (ESTs) and DNA microarrays. ORF: open reading frame

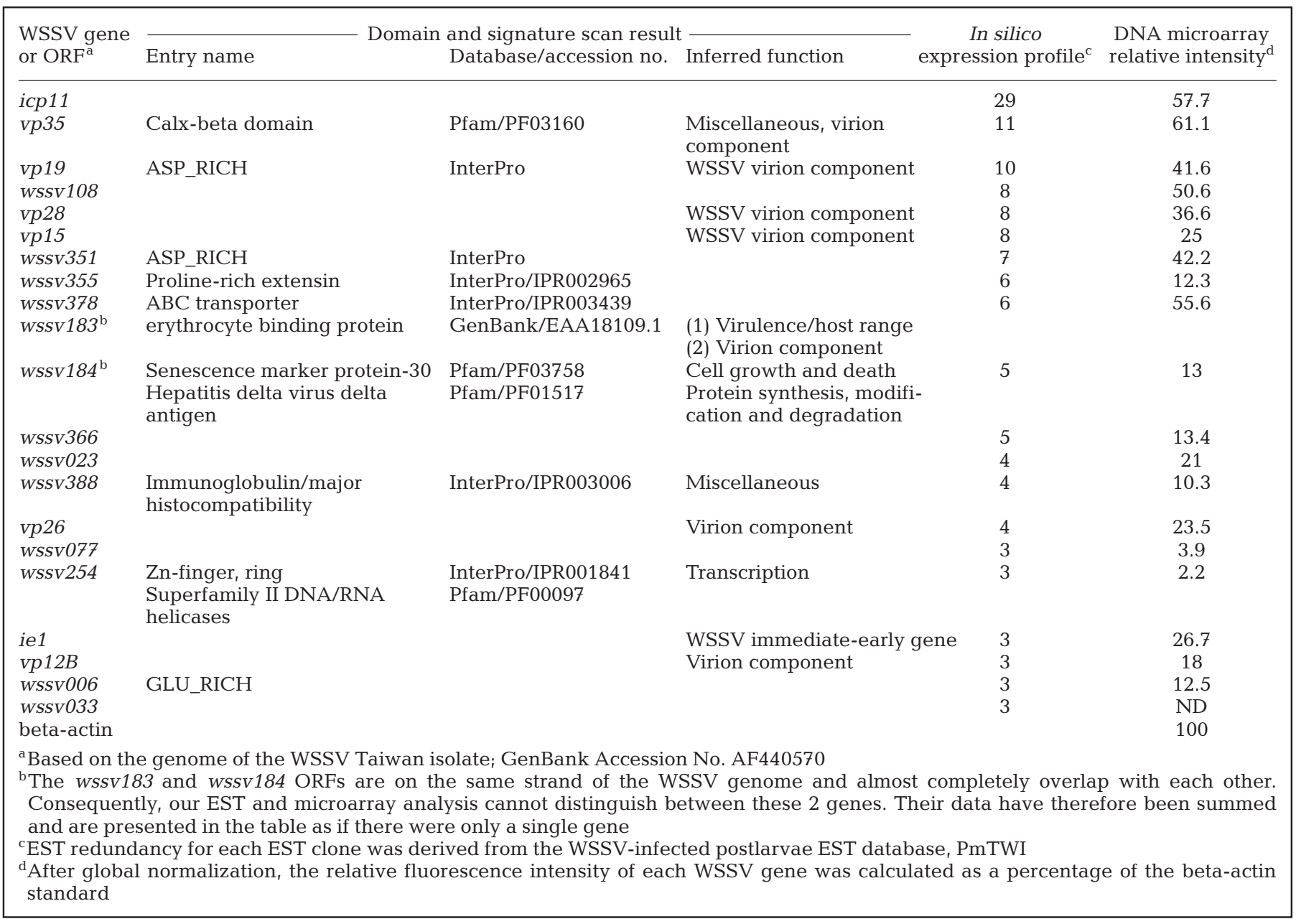

redundancy $=8$ ). Other strongly expressed WSSV genes included several other WSSV structural genes (vp19, vp28, vp15, vp26, vp12b, vp38a), the immediate gene (ie1) and other genes with unknown functions.

In support of these results, the expression profiles obtained from the WSSV microarray chips (Table 1, last column) were broadly consistent with the in silico expression profiles.

\section{Identification of expressed WSSV proteins in WSSV-infected shrimp gill using 2-DE}

The 2-DE protein expression profiles (Fig. 1) show that WSSV ICP11 was highly expressed at the protein level in the WSSV-infected gill tissue at $48 \mathrm{hpi}$. The identification of the ICP11 protein was confirmed by LC-nanoESI-MS/MS. The sequence coverage was $52 \%$, and matching peptides are shown underlined in Fig. 2. Similar results were found in our previous study, which showed that ICP11 protein expression levels were also elevated in stomach cells after WSSV infection (Wang et al. 2007). The expression levels of the control/normalizing protein, beta-actin, and of shrimp arginine kinase did not vary significantly after infection, and confirmed the comparability of the gels. These 2-DE results for WSSV ICP11 were in good agreement with the EST database and DNA microarray results (Table 1), and suggest that ICP11 is highly expressed at both the transcription and translation levels. We note too that no other viral protein was detected in any of the 2-DE gels.

\section{Nucleotide and amino acid sequence of the icp11 cDNA coding sequence}

The icp11 ORF (wssv285 in the Taiwan isolate) comprises only 249 nuceotides (nt), with the potential to encode a putative protein of 82 amino acids with a 

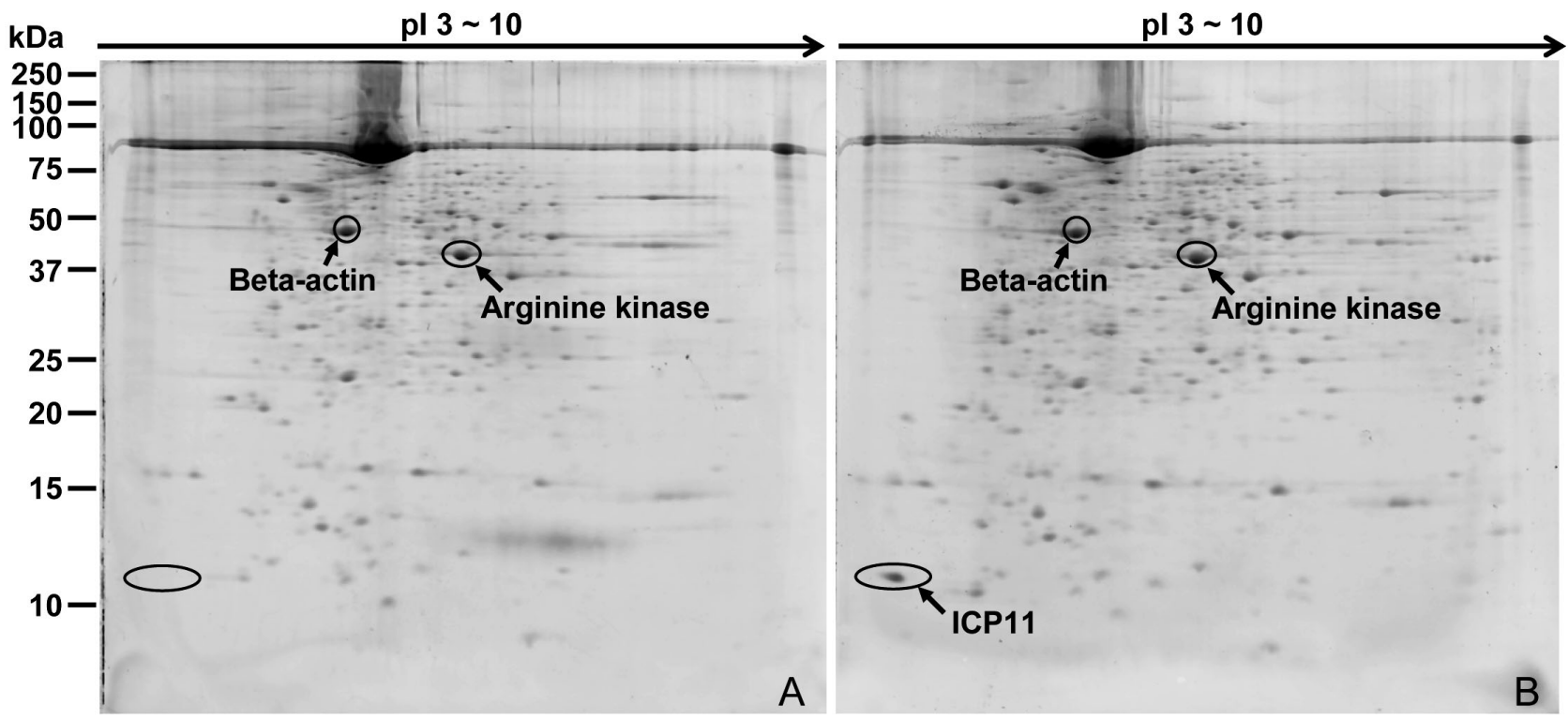

Fig. 1. Two-dimensional gel electrophoresis profiles of cytoplasmic proteins in Litopenaeus vannamei gills at 48 hpi. (A) Phosphate-buffered saline control and (B) white spot syndrom virus (WSSV)-infected. Circled spots contain the indicated virus or shrimp proteins, as determined by liquid chromatography-nano-electrospray ionization tandem mass spectrometry (LC-nanoESI-MS/MS). pI: isoelectric point

predicted molecular mass of $9.2 \mathrm{kDa}$. The protein is predicted to have an isoelectric point (pI) of 4.2 . Observed values based on 2-DE image analysis (11.3 and 3.4, respectively; Fig. 1) were in good agreement with these predictions. The sequence of WSSV icp11 mRNA, as determined by $5^{\prime} / 3^{\prime}$ RACE, is shown in Fig. 2. The transcriptional initiation site of WSSV icp11 was located $63 \mathrm{nt}(\mathrm{T})$ upstream of the putative ATG initiation codon. The nucleotides around and upstream of the transcriptional initiation site did not include a putative TATA box (TATAAA) or initiator motif (CAGT), indicating that WSSV icp11 could be a late gene. Sequence analysis of the cloned 3'RACE products indicated that poly (A) was added at a site 15 nt downstream of the AATAAA polyadenylation signal (Fig. 2).

A computer search of the SWISS-PROT and InterPro and Pfam databases revealed no significant

- 120 ACTTTTTGTCACCCTCATGAATACAATTTGTAAAGGTGCTGAAATGTACTTGTTTTTTAT-61

- 60 CCAAATTTCCTGTACTGAAGAATATTGAAAGAAGACTTCTTGAAGAGGACCGATAAAAAA - 1

1 ATGGCCACCTTCCAGACTGACGCCGATTTCTTGCTGGTGGGGGATGATACTAGTAGATAT 60 $\begin{array}{llllllllllllllllllll}M & A & T & F & Q & T & D & A & D & F & L & L & V & G & D & D & T & S & R & Y\end{array}$

61 GAAGAAGTGATGAAGACTTTTGATACTGTTGAGGCAGTCAGGAAGAGTGATCTAGATGAC 120 $\begin{array}{llllllllllllllllllll}E & E & V & M & K & T & F & D & T & Y & E & A & V & R & K & S & D & L & D & D\end{array}$

121 CGTGTTTACATGGTGTGCCTAAAGCAGGGATCTACTTTTGTCCTCAATGGAGGCATCGAA 180 \begin{tabular}{llllllllllllllllllll}
$R$ & $V$ & $Y$ & $M$ & $V$ & $C$ & $L$ & $K$ & $Q$ & $G$ & $S$ & $T$ & $F$ & $Y$ & $L$ & $N$ & $G$ & $G$ & $I$ & $E$ \\
\hline
\end{tabular}

181 GAATTGCGTCTTTTGACTGGAGATTCAACGCTGGAGATTCAACCCATGATTGTGCCAACA 240 \begin{tabular}{llllllllllllllllllll}
$E$ & $\mathrm{~L}$ & $\mathrm{R}$ & $\mathrm{L}$ & $\mathrm{L}$ & $\mathrm{T}$ & $\mathrm{G}$ & $\mathrm{D}$ & $\mathrm{S}$ & $\mathrm{T}$ & $\mathrm{L}$ & $\mathrm{E}$ & $\mathrm{I}$ & $\mathrm{Q}$ & $\mathrm{P}$ & $\mathrm{M}$ & $\mathrm{I}$ & $\mathrm{V}$ & $\mathrm{P}$ & $\mathrm{T}$ \\
\hline
\end{tabular}

241 ACAGAATAAAATAAAGACGGTGACGGGAGACTAATATCTTTCTTAGTTTCCCGTCACGGT 300 $\underline{\mathrm{T}} \mathrm{E}$ *

301 GAAAATGTTGGTTATTTCTTCCCTATGTTTAAAAATTTGTCTTGGTTAAAAAAATAAAAC 360

361 GAAAACTGTCAATATATTGTTTTATTGATATACAATATCCCTTTTTACACAGAAATGGCA 420 $\uparrow$

Fig. 2. WSSV icp11 gene and deduced amino acid sequence. Bent arrow indicates the transcriptional initiation site. The polyadenylation signal (AATAAA) is in bold print. Straight arrow indicates the poly (A) addition site. Underlined amino acids indicate the sequence identified by LC-nanoESI-MS/MS data. *: stop codon 

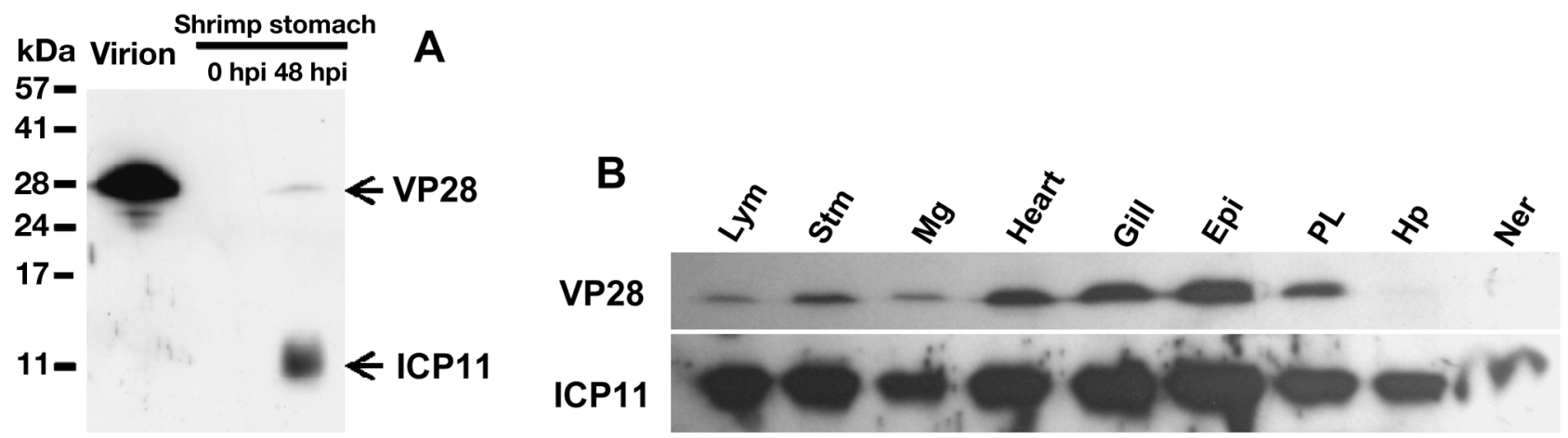

Fig. 3. (A) Western blot expression analysis of WSSV ICP11 and VP28 at the protein level in the purified WSSV virion, and in shrimp stomachs before (0 hpi) and after (48 hpi) WSSV infection. (B) Protein expression levels of ICP11 and VP28 in 9 WSSVinfected shrimp organs at 48 hpi: lymphoid organ (Lym), stomach (Stm), midgut (Mg), heart, gill, epidermis (Epi), pleopod (PL), hepatopancreas $(\mathrm{Hp})$ and nervous tissue (Ner)

similarity to any known protein sequence (Altschul et al. 1990, Bateman et al. 2002, Mulder et al. 2003). No sequence that was associated with subcellular localization or protein targeting, such as a transmembrane domain or signal peptide, was observed, which suggests that the protein may be soluble and localized in either the cytoplasm or the nucleus.

\section{Expression of WSSV ICP11 in WSSV-infected shrimp}

WSSV ICP11-specific antibody detected native WSSV ICP11 in lysate from WSSV-infected Penaeus monodon shrimp stomach at $48 \mathrm{hpi}$. The molecular mass of WSSV ICP11 was $11 \mathrm{kDa}$, which is approximately $2 \mathrm{kDa}$ greater than the computed mass $(9 \mathrm{kDa})$ (Fig. 3A). Western blotting failed to confirm the presence of WSSV ICP11 in the WSSV virion (Fig. 3A), suggesting that WSSV ICP11 is a non-structural protein that does not exist in the WSSV virion particle. By contrast, Western blotting with a WSSV VP28-specific antibody on the same PVDF membrane detected a $28 \mathrm{kDa}$ band in both the virion and the stomach tissue lysate (Fig. 3A). The tissue tropism analysis (Fig. 3B) demonstrates that, while VP28 could be detected in all but 2 of the tested organs, WSSV ICP11 was present in every tested organ, including the hepatopancreas and nervous tissue, and also that it was expressed more strongly than VP28.

Fig. 4 shows the results of protein dotblot analysis that used WSSV VP28and WSSV ICP11-specific antibodies to screen for WSSV, not only in healthy and experimentally infected Penaeus monodon, but also in naturally infected P. monodon that were collected from a shrimp culture farm and diagnosed as 1-step WSSV positive by PCR (Hsu et al. 1999). The WSSV ICP11specific antibody was capable of clearly detecting WSSV infection in, respectively, 2.5 and $1 \mu \mathrm{g}$ of total protein in gill tissue lysate from the naturally and experimentally WSSV-infected shrimp. In the same samples, and using the same exposure time, the detection results for VP28 were much fainter.

\section{WSSV ICP11 in the cytoplasm and nucleus of shrimp hemocyte cells}

To determine the subcellular localization of ICP11 during WSSV infection, shrimp hemocytes were collected at $24 \mathrm{hpi}$, cultured on slides for $2 \mathrm{~h}$, fixed with

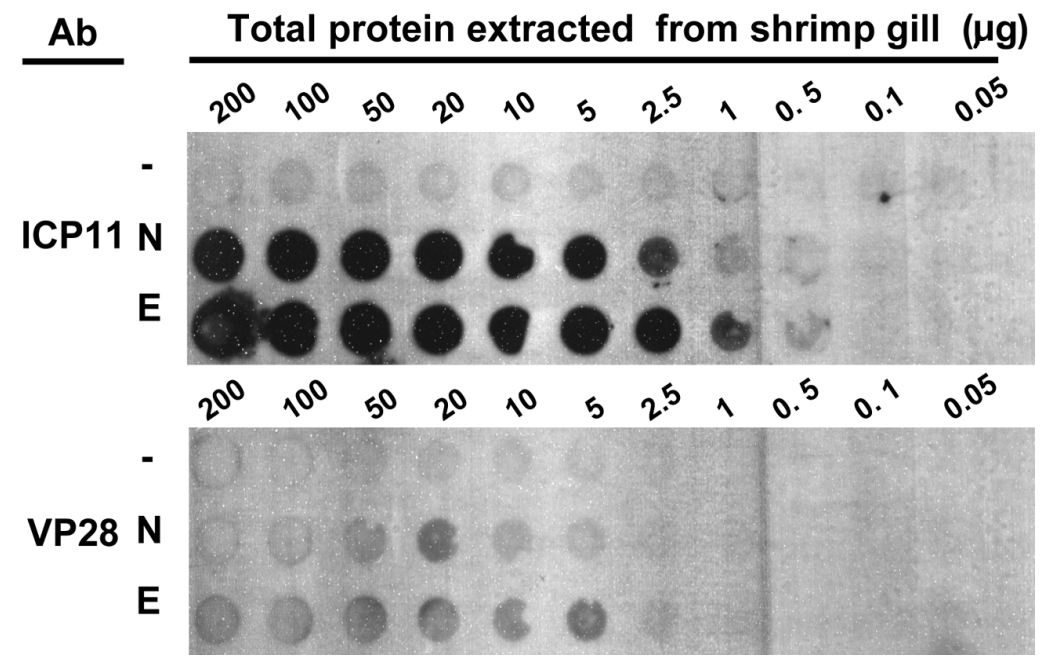

Fig. 4. Protein dot-blot detection for different quantities of gill tissue lysate extracted from healthy (-), naturally WSSV-infected $(\mathrm{N})$, and experimentally WSSV-infected (E) Penaeus monodon using antisera of ICP11 and VP28 

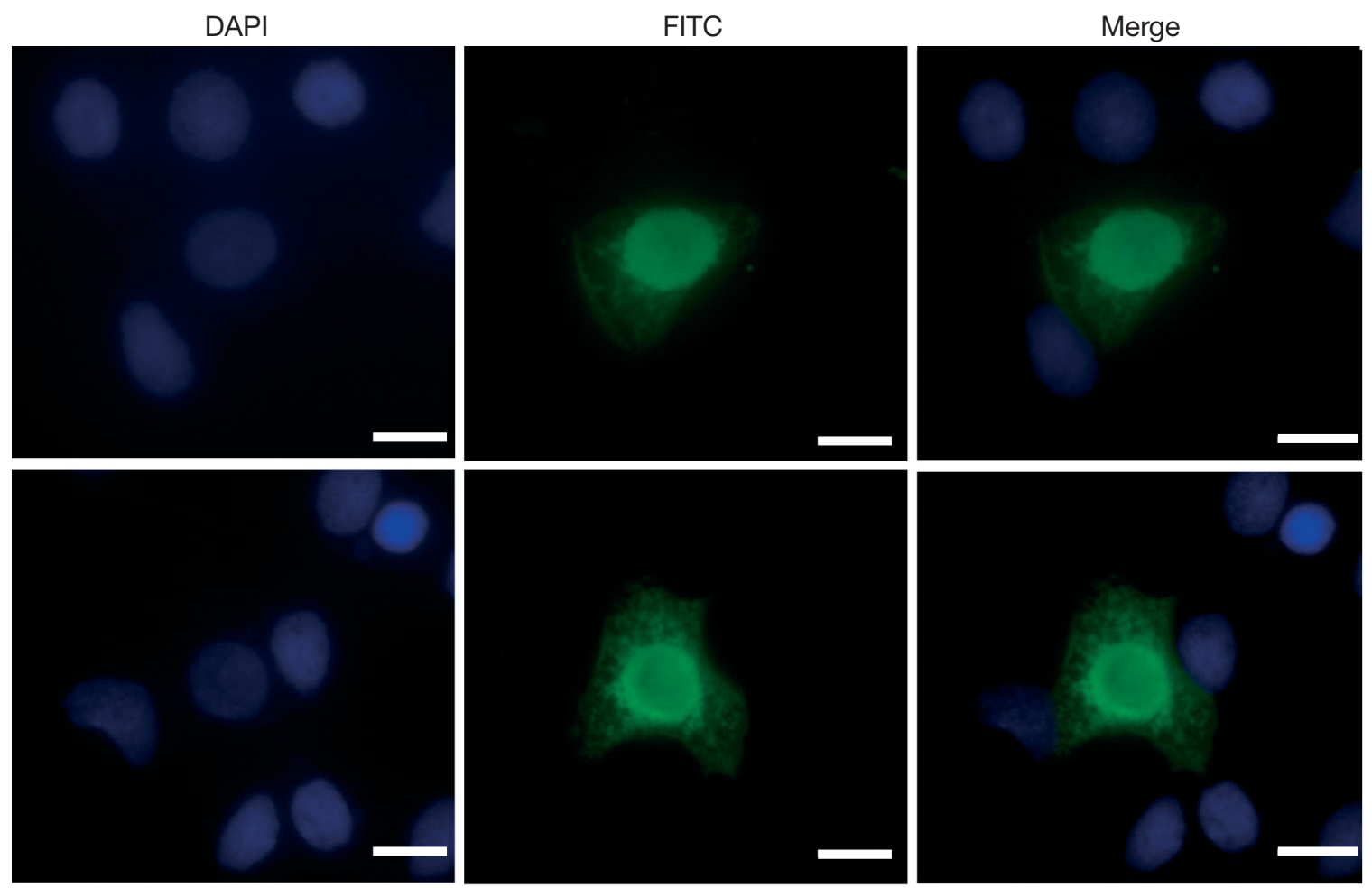

Fig. 5. Localization of WSSV ICP11. Light micrographs of hemocytes collected from WSSV-infected shrimp that were reacted first with antibodies specific to WSSV ICP11, and then with fluorescein isothiocyanate (FITC)-conjugated goat anti-rabbit immunoglobulin G (IgG) antibody; 4', 6-diamidino-2-phenylindole (DAPI) was used to counterstain (blue fluorescence) the nuclear DNA of the shrimp hemocytes. Scale bars $=10 \mu \mathrm{m}$

paraformaldehyde and examined by fluorescence microscopy. As Fig. 5 shows, ICP11 was observed both in the cytoplasm and the nucleus. Since ICP11 does not have a nuclear localization signal, its localization in the nucleus may require the involvement of other viral components or host factors. In Fig. 5, positive signals are only seen in WSSV-infected cells, which suggests that there was no non-specific cross reaction with host proteins. This was confirmed by the absence of any cross reaction when healthy shrimp hemocytes were incubated with anti-rICP11 (data not shown).

\section{Multimeric nature of rICP11}

To study the multimerization of rICP11, we used a chemical cross-linking assay followed by analysis with
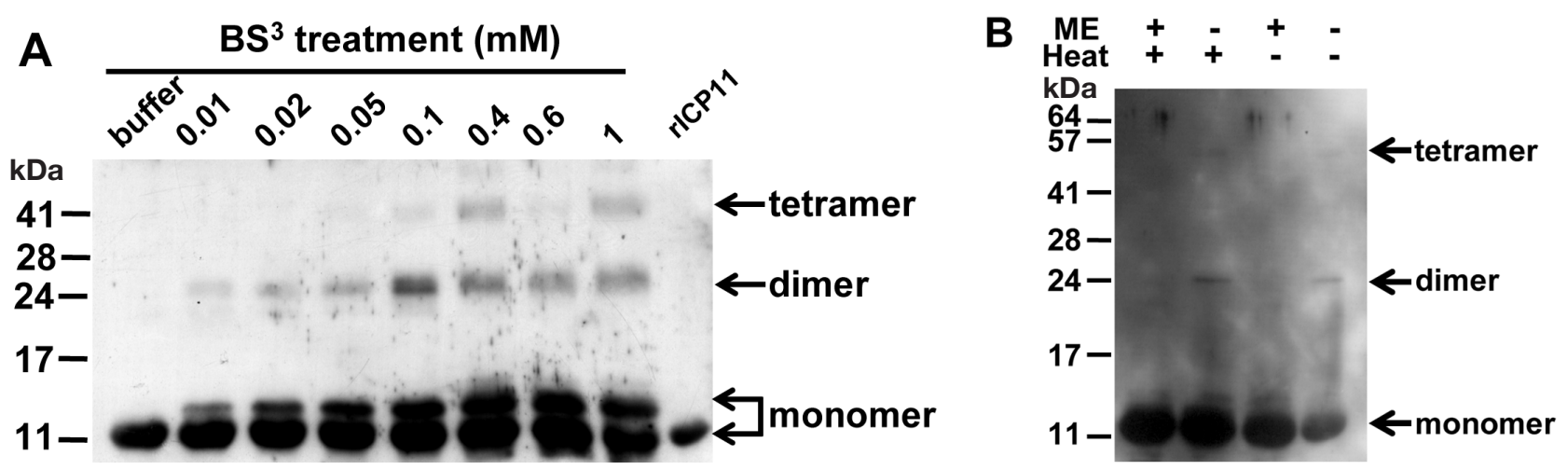

Fig. 6. Multimeric nature of rICP11. (A) Chemical cross-linking was performed for 30 min by applying the indicated amounts of bis(sulfosuccinimidyl) suberate $\left(\mathrm{BS}^{3}\right)$ to purified rICP11. Visible bands represent the monomer $(12 \mathrm{kDa})$, dimer $(24 \mathrm{kDa})$ and tetramer (48 kDa) forms. (B) Purified rICP11 was analyzed by Western blotting in the presence (+) or absence (-) of $1 \%$ betamercaptoethanol (ME), either with $(+)$ or without $(-)$ heat treatment 
SDS-PAGE and immunoblotting (Fig. 6A). In the absence of the $\mathrm{BS}^{3}$ cross-linker, rICP11 appeared to be in monomeric form (with molecular mass $\sim 1 \mathrm{kDa}$ greater than the native ICP11 band because of the additional His-tag).

However, in the presence of $\mathrm{BS}^{3}$, which acts to stabilize multimers by forming covalent bonds between amino groups in the target proteins, SDS-PAGE followed by immunoblotting revealed 3 additional major products. The first band migrated just slightly more slowly than the untreated proteins. We follow Song et al. (2004) and interpret this band to be the result of intramolecular cross-linking between rICP11 and BS ${ }^{3}$. Two other bands migrated with apparent molecular weights of 24 and $48 \mathrm{kDa}$. The intensity of all 3 of these bands increased with increasing concentrations of $\mathrm{BS}^{3}$, and we interpret the 2 higher mass bands as evidence of the presence of rICP11 dimers and tetramers, respectively. These 2 multimer bands were not found after treatment with the reducing agent beta-mercaptoethanol (Fig. 6B), but were still detected after heat treatment alone (Fig. 6B, Lanes 2 and 4 ; the $48 \mathrm{kDa}$ bands are very faint). These data suggest that at least the dimerization of rICP11 is mediated by a disulfide bond.

\section{DISCUSSION}

In the present study, we used global methods to show that the non-structural protein ICP11 is the most highly expressed WSSV gene at both transcriptional and translational levels (Table 1, Fig. 1). The protein sequence of ICP11 is very unique, and its function will need to be further elucidated. However, the present finding is already a very significant contribution to the study of WSSV genomics.

For several viruses, such as the varicella-zoster virus, even though some pathogenesis-related, non-structural proteins are highly expressed (Kennedy et al. 2005), the most abundant virus transcripts expressed during virus propagation are associated with the membrane structure or capsid assemblies (Cohrs et al. 2003). In other viruses, such as vaccinia virus and Amsacta moorei entomopoxvirus (AmEPV), the most highly expressed genes, ORF A26L and spheroidin, respectively, are necessary for the formation of inclusion/occlusion bodies (Tartaglia et al. 1992, Li et al. 1998). In AmEPV-infected cells, spheroidin alone accounts for up to $30-40 \%$ of the total protein of infected insect cells (Winter et al. 1995). WSSV also has several highly expressed structural genes/proteins, and, to date, the major structural protein VP28 has been the most commonly used WSSV target for immuno-based detection (Liu et al. 2002, Yoganand- han et al. 2004). Here, however, we have shown that the transcription expression levels of ICP11 are approximately $3 \times$ greater than those of VP28. Fig. 1 also shows that ICP11 was expressed at $48 \mathrm{hpi}$, and, at this time, VP28 was still not detectable in the 2-DE gels (data not shown). ICP11 is evidently not a structural protein (see Fig. 3A), and, although its function remains unknown, we conclude that this non-structural protein is the most highly expressed viral protein in WSSV-infected cells.

The ability of ICP11 to form multimers (Fig. 6) may help to account for its localization in both the nucleus and cytoplasm of most of the WSSV-infected cells (Fig. 5). Self-association is known to affect the nucleocytoplasmic transport of many proteins, such as human Class II transactivator (CIITA) and p53 (Stommel et al. 1999, Kretsovali et al. 2001). Thus, although CIITA has 2 nuclear localization signal (NLS) motifs, sequence mutation data have shown that selfassociation is necessary for CIITA to be recognized by the nuclear import machinery (Kretsovali et al. 2001). Conversely, only the monomeric or dimeric forms of p53 are able to use the protein's intrinsic nuclear export signal (NES) to mediate its export from the nucleus to the cytoplasm, because when p53 occurs as a tetramer, the NES is masked (Stommel et al. 1999). In the case of ICP11, more work will be needed to establish the functional significance (if any) of its ability to form dimers and tetramers. Our data suggest that the dimerization of ICP11 is the result of disulfide bond formation, but, as there is only 1 cysteine residue (Cys 46) in the ICP11 monomer, it follows that disulfide bonding can only occur between pairs of monomers. A different mechanism must therefore be involved in the formation of the ICP11 tetramers. The most likely mechanism would be via a noncovalent (ionic, hydrophobic) interaction (Kang et al. 2003), and we note that other multimers, such as those of the protein-arginine methyltransferases, are also formed by a combination of covalent and noncovalent associations (Rho et al. 2001).

In summary, WSSV ICP11 is a novel, infected cell protein of unknown function that is the most highly expressed viral protein at transcriptional and translational levels. Apart from suggesting that ICP11 may play an important role during viral infection, in this study we found that the levels of this gene/protein in infected shrimp are much higher than the most highly expressed structural gene/protein, VP28. This makes ICP11 potentially a very good target for developing RNA-based and immuno-based detection methods. ICP11 is present throughout the body of infected shrimp and even in hemolymph, which is very convenient when preparing samples for diagnosis. The protein is also very small (molecular weight $[\mathrm{MW}]=$ 
$11 \mathrm{kDa}$ ) and acidic ( $\mathrm{pI}=4.2$ ), which means that a specific column could easily be used to optimize the sample for immuno-detection and to decrease interference from non-specific cross-reactions. Taken together, all of these properties suggest that it should be relatively straightforward to use ICP11 as the basis of an easy-to-use, commercial, pond-side diagnostic kit. Currently, most of the available WSSV diagnostic kits are PCR based, and, although these kits are effective and widely used in research laboratories, they are cumbersome and difficult to use in the field. An easily performed, immuno-based ICP11 detection method would therefore be a very welcome technology for the shrimp culture industry.

Acknowledgements. This investigation was supported financially by National Science Council grants (NSC-94-2317-B002-011 and NSC-94-2317-B-002-022) and by the Council of Agriculture (95AS-13.4.1-AQ-B4). Proteomic mass spectrometry analyses were performed by the Core Facilities for Proteomics Research located at the Institute of Biological Chemistry, Academia Sinica. We are also indebted to Paul Barlow for his helpful criticism.

\section{LITERATURE CITED}

Altschul SF, Gish W, Miller W, Myers EW, Lipman DJ (1990) Basic local alignment search tool. J Mol Biol 215:403-410

Bateman A, Birney E, Cerruti L, Durbin R and 6 others (2002) The Pfam protein families database. Nucleic Acids Res 30:276-280

Chang CF, Su MS, Kou GH (1995) Purification and genomic analysis of baculovirus associated with white spot syndrome (WSBV) of Penaeus monodon. Dis Aquat Org 23:239-242

Chen LL, Lo CF, Chiu YL, Chang CF, Kou GH (2000) Natural and experimental infection of white spot syndrome virus (WSSV) in benthic larvae of mud crab Scylla serrata. Dis Aquat Org 40:157-161

Chen LL, Leu JH, Huang CJ, Chou CM, Chen SM, Wang CH, Lo CF, Kou GH (2002) Identification of a nucleocapsid protein (VP35) gene of shrimp white spot syndrome virus and characterization of the motif important for targeting VP35 to the nuclei of transfected insect cells. Virology 293: $44-53$

Cohrs RJ, Hurley MP, Gilden DH (2003) Array analysis of viral gene transcription during lytic infection of cells in tissue culture with varicella-zoster virus. J Virol 77: 11718-11732

Hassan SS, Roy P (1999) Expression and functional characterization of bluetongue virus VP2 protein: role in cell entry. J Virol 73:9832-9842

Hsu HC, Lo CF, Lin SC, Liu KF and 5 others (1999) Studies on effective PCR screening strategies for white spot syndrome virus (WSSV) detection in Penaeus monodon brooders. Dis Aquat Org 39:13-19

Kang YK, Yoon T, Lee K, Kim HJ (2003) Homo- or heterodimerization of muscarinic receptor subtypes is not mediated by direct protein-protein interaction through intracellular and extracellular regions. Arch Pharmacol Res 26:846-854

Kaukinen P, Koistinen V, Vapalahti O, Vaheri A, Plyusnin A
(2001) Interaction between molecules of hantavirus nucleocapsid protein. J Gen Virol 82:1845-1853

Kennedy PG, Grinfeld E, Craigon M, Vierlinger K, Roy D, Forster T, Ghazal P (2005) Transcriptomal analysis of varicella-zoster virus infection using long oligonucleotidebased microarrays. J Gen Virol 86:2673-2684

Kretsovali A, Spilianakis C, Dimakopoulos A, Makatounakis T, Papamatheakis J (2001) Self-association of class II transactivator correlates with its intracellular localization and transactivation. J Biol Chem 276:32191-32197

Leu JH, Tsai JM, Wang HC, Wang AH, Wang CH, Kou GH, Lo CF (2005) The unique stacked rings in the nucleocapsid of the white spot syndrome virus virion are formed by the major structural protein VP664, the largest viral structural protein ever found. J Virol 79:140-149

Li Y, Hall RL, Yuan SL, Moyer RW (1998) High-level expression of Amsacta moorei entomopoxvirus spheroidin depends on sequences within the gene. J Gen Virol 79: 613-622

Lightner DV (2003) Exclusion of specific pathogens for disease prevention in a penaeid shrimp biosecurity program. In: Lee CS, O'Bryen PJ (eds) Biosecurity in aquaculture production systems: exclusion of pathogens and other undesirables. World Aquaculture Society, Baton Rouge, LA, p 81-116

Lin ST, Chang YS, Wang HC, Tzeng HF and 5 others (2002) Ribonucleotide reductase of shrimp white spot syndrome virus (WSSV): expression and enzymatic activity in a baculovirus/insect cell system and WSSV-infected shrimp. Virology 304:282-290

Liu W, Wang YT, Tian DS, Yin ZC, Kwang J (2002) Detection of white spot syndrome virus (WSSV) of shrimp by means of monoclonal antibodies (MAbs) specific to an envelope protein (28 kDa). Dis Aquat Org 49:11-18

Liu WJ, Chang YS, Wang CH, Kou GH, Lo CF (2005) Microarray and RT-PCR screening for white spot syndrome virus immediate-early genes in cycloheximide-treated shrimp. Virology 334:327-341

Lo CF, Kou GH (1998) Virus-associated white spot syndrome of shrimp in Taiwan: a review. Fish Pathol 3:365-371

Lo CF, Ho CH, Chen CH, Liu KF and 9 others (1997) Detection and tissue tropism of white spot syndrome baculovirus (WSBV) in captured brooders of Penaeus monodon with a special emphasis on reproductive organs. Dis Aquat Org 30:53-72

Lo CF, Hsu HC, Tsai MF, Ho CH, Peng SE, Kou GH, Lightner DV (1999) Specific genomic DNA fragment analysis of different geographical clinical samples of shrimp white spot syndrome virus. Dis Aquat Org 35:175-185

Lu Y, Tapay LM, Loh PC, Brock JA, Gose R (1997) The pathogenicity of a baculo-like virus isolate from diseased penaeid shrimp obtained from China for cultured penaeid species in Hawaii. Aquat Int 5:277-282

Mulder NJ, Apweiler R, Attwood TK, Bairoch A and 33 others (2003) The InterPro Database, 2003 brings increased coverage and new features. Nucleic Acids Res 31: 315-318

Okumura T, Nagai F, Yamamoto S, Oomura H, Inouye $\mathrm{K}$, Ito M, Sawada H (2005) Detection of white spot syndrome virus (WSSV) from hemolymph of penaeid shrimps Penaeus japonicus by reverse passive latex agglutination assay using high-density latex particles. J Virol Methods 124:143-148

Peng SE, Lo CF, Lin SC, Chen LL, Chang YS, Liu KF, Su MS, Ko GH (2001) Performance of WSSV-infected and WSSVnegative Penaeus monodon postlarvae in culture ponds. Dis Aquat Org 46:165-172 
Rho J, Choi S, Seong YR, Cho WK, Kim SH, Im DS (2001) Prmt5, which forms distinct homo-oligomers, is a member of the protein-arginine methyltransferase family. J Biol Chem 276:11393-11401

Sangamaheswaran AP, Jeyaseelan MJP (2001) White spot viral disease in penaeid shrimp - a review. ICLARM $Q$ 24:16-22

Song BD, Yarar D, Schmid SL (2004) An assembly-incompetent mutant establishes a requirement for dynamin selfassembly in clathrin-mediated endocytosis in vivo. Mol Biol Cell 15:2243-2252

Stommel JM, Marchenko ND, Jimenez GS, Moll UM, Hope TJ, Wahl GM (1999) A leucine-rich nuclear export signal in the p53 tetramerization domain: regulation of subcellular localization and p53 activity by NES masking. EMBO J 18:1660-1672

Tartaglia J, Perkus ME, Taylor J, Norton EK and 8 others (1992) NYVAC: a highly attenuated strain of vaccinia virus. Virology 188:217-232

Tsai MF, Kou GH, Liu HC, Liu KF and 5 others (1999) Longterm presence of white spot syndrome virus (WSSV) in a cultivated shrimp population without disease outbreaks. Dis Aquat Org 38:107-114

Tsai JM, Wang HC, Leu JH, Hsiao HH, Wang AH, Kou GH, Lo CF (2004) Genomic and proteomic analysis of thirty-nine structural proteins of shrimp white spot syndrome virus. J Virol 78:11360-11370

Tsai JM, Wang HC, Leu JH, Wang AH, Zhuang Y, Walker PJ, Kou GH, Lo CF (2006) Identification of the nucleocapsid, tegument, and envelope proteins of the shrimp white spot syndrome virus virion. J Virol 80:3021-3029

Valk JM, Flegel BTW, Kou GH, Lightner DV, Lo CF, Loh PC, Walker PW (2004) Nimaviridae. In: Fauquet CM, Mayo

Editorial responsibility: Timothy Flegel,

Bangkok, Thailand
MA, Maniloff J, Desselberger U, Ball LA (eds) VIIIth report of the International Committee on Taxonomy of Viruses. Elsevier, Amsterdam, p 187-192

Wang $\mathrm{CH}$, Lo CF, Leu JH, Chou CM and 6 others (1995) Purification and genomic analysis of baculovirus associated with white spot syndrome (WSBV) of Penaeus monodon. Dis Aquat Org 23:239-242

Wang HC, Lin AT, Yii DM, Chang YS, Kou GH, Lo CF (2004) DNA microarrays of the white spot syndrome virus genome: gene expressed in the gills of infected shrimp. Mar Biotechnol S6:106-111

Wang $\mathrm{HC}$, Wang $\mathrm{HC}$, Leu JH, Kou GH, Wang AH, Lo CF (2007) Protein expression profiling of the shrimp cellular response to white spot syndrome virus infection. Dev Comp Immunol doi:10.1016/j.dci.2006.11.001

Winter J, Hall RL, Moyer RW (1995) The effect of inhibitors on the growth of the entomopoxvirus from Amsacta moorei in Lymantria dispar (gypsy moth) cells. Virology 211:462-473

Wongteerasupaya C, Vickers JE, Sriurairatana S, Nash GL and 6 others (1995) A non-occluded, systemic baculovirus that occurs in cells of ectodermal and mesodermal origin and causes high mortality in the black tiger prawn Penaeus monodon. Dis Aquat Org 21:69-77

Yoganandhan K, Syed Musthaq S, Narayanan RB, Sahul Hameed AS (2004) Production of polyclonal antiserum against recombinant VP28 protein and its application for the detection of white spot syndrome virus in crustaceans. J Fish Dis 27:517-522

Yu J, Farjo R, MacNee SP, Baehr W, Stambolian DE, Swaroop A (2003) Annotation and analysis of 10000 expressed sequence tags from developing mouse eye and adult retina. Genome Biol 4: R65

Submitted: September 25, 2006; Accepted: November 16, 2006 Proofs received from author(s): February 24, 2007 